\title{
PANCREATIC MUCINOUS CYSTIC NEOPLASM
}

\section{Muhammad Fahd Shah, Faisal Hanif}

Department of Surgical Oncology, Shaukat Khanum Memorial Cancer Hospital and Research Centre, Lahore, Pakistan

Received: 9 August 2016 / Accepted: 26 August 2016

A 37-year-old female with no comorbid was in usual state of health 1 month back when she started having abdominal pain. It was more marked on the left side and radiated to back. Pain was relieved by analgesics and was not associated with nausea or vomiting. There was no past history of jaundice or weight loss. On examination, there was a swelling in the abdomen which was gradually increasing in size.

Investigations showed CA - 19.9 level to be $26.9 \mathrm{U} / \mathrm{ml}$. Computed tomography of the abdomen showed cystic mass arising from the pancreatic body with internal septations and measured around $14 \mathrm{~cm}$ [Figure 1]. On endoscopic ultrasound, there was a large mass between the spleen and liver, the origin of which could not be ascertained. CEA levels of cystic fluid were $9557 \mathrm{ng} / \mathrm{ml}$. Fine needle aspiration of mass showed mucinous cystic adenoma.

The case was discussed in multidisciplinary meeting and it was decided to proceed with surgery as the patient belonged to a high-risk group according to Sendai consensus guidelines. Surgery was performed and showed large mass arising from the distal pancreas; therefore, distal pancreatectomy and splenectomy were performed [Figure 2]. Histopathology showed mucinous cystic neoplasm with intermediate-grade dysplasia.

Tumour was $0.5 \mathrm{~mm}$ from closest posterior margin. The spleen did not show any significant pathology. 10 nodes were identified which were reactive.

There have been few studies in literature describing the nature of pancreatic mucinous cystic neoplasms. ${ }^{[1]}$ These neoplasms can occur in any part of the pancreas. Solid pseudopapillary tumours are rare, have a low tendency for

Correspondence: Dr. Muhammad Fahd Shah, Department of Surgical Oncology, Shaukat Khanum Memorial Cancer Hospital and Research Centre, Lahore, Pakistan. Email: dr_fahdshah@hotmail.com malignancy ${ }^{[2,3]}$ and are usually located in the pancreatic body or tail. Endoscopic ultrasound has emerged as the investigation of choice for diagnosing such lesions. ${ }^{[4]}$ Sendai consensus guidelines have classified patients into

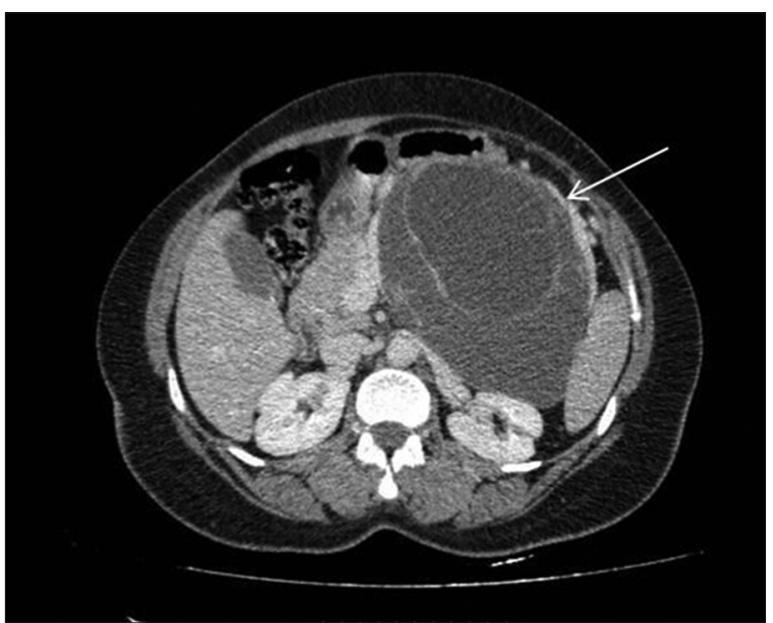

Figure 1: Axial contrast-enhanced computed tomography image showing a large well-encapsulated predominantly cystic multiloculated tumour arising from body and tail of the pancreas (white arrow)

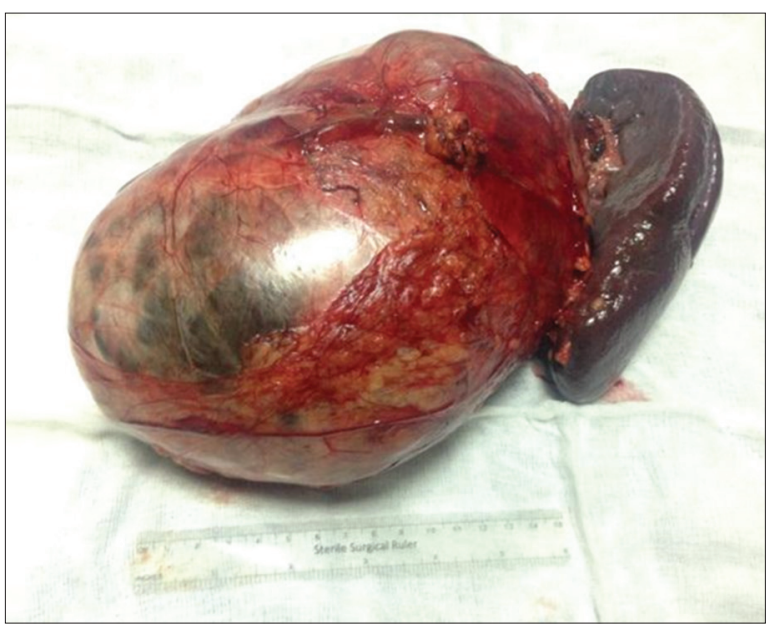

Figure 2: Resected specimen showing distal pancreas with cyst and spleen, removed in toto 
high- and low-risk groups for malignancy. Patients who are symptomatic, lesions $>3 \mathrm{~cm}$, solid component and dilatation of main pancreatic duct were classified as high-risk group. ${ }^{[5]}$

\section{Conflict of Interest}

The authors declare that they have no conflict of interest.

\section{References}

1. Karoumpalis I, Christodoulou DK. Cystic lesions of the pancreas. Ann Gastroenterol 2016;29:155-61.

2. Munekage M, Kohsaki T, Uemura S, et al. Mucinous cystadenocarcinoma of the pancreas with anaplastic carcinoma: A case report and review of the literature. Mol Clin Oncol 2016;4:483-6.

3. Parra V, Acero F, Alvarez E, et al. A case of mucinous cystic neoplasm from a gastric ectopic pancreas. Gastrointest Endosc 2017;85:1096-7.

4. Kim YI, Woo SM, Lee WJ, et al. Appropriate indications of initial endoscopic ultrasound evaluation for detecting mural nodules in branch duct intraductal papillary mucinous neoplasms of the pancreas. Scand J Gastroenterol 2013;48:610-6.

5. Vázquez AM, Hernández AC, Norris AL, et al. What to do with an intraductal papilary mucinous pancreatic neoplasm? Our experience. Cir Esp 2016;94:462-72. 